Www.jmscr.igmpublication.org

Index Copernicus Value: 79.54

ISSN (e)-2347-176x ISSN (p) 2455-0450

crossref DOI: https://dx.doi.org/10.18535/jmscr/v7i6.03

\title{
Broken Intravenous Angiocath - A Case Series
}

Authors

\section{Bakhshi GD, Parikh AK*, Rahul K, Bagul AG, Gangawane SD}

Department of Surgery, Grant Government Medical College and Sir JJ Group of Hospitals, Mumbai 400008, Maharashtra, India

*Corresponding Author

Dr Parikh AK

Address: 15, Asha Mahal, 46B Pedder Road, Mumbai 400026, Maharashtra, India

\begin{abstract}
Insertion of peripheral intravenous (I.V.)lines is a key component for almost every patient who arrives to casualty for seeking treatment. In adults, routinely $18 \mathrm{G}$ or $20 \mathrm{G}$ plastic cannula are used. Although placement of these invasive devices is seen as a benign part of the daily practice particularly by junior staff, many complications like infiltration, thrombophlebitis, venous spasm, hematoma, air embolism, cannula associated blood stream infection and nerve, tendon and ligament injury can occur. Fracture of I.V. canula inside the vein is rare. We present a case series of 2 patients who presented with such complications. A brief case series \& review of literature is presented.
\end{abstract}

Keywords: Fracture intravenous canula.

\section{Introduction}

Foreign bodies are encountered on daily basis by surgeons. Foreign bodies are generally found lodged in narrow cavities of the body ranging from the ear, nose, cricopharynx and even in rectum. Foreign Bodies are more common in children. Iatrogenic foreign bodies are not uncommon. There have been cases of sponges as well as surgical instruments being left accidentally in the abdomen which lead to hazardous sequelae. Intravascular foreign bodies are a rare occurrence. We would like to present 2 cases of iatrogenic intravascular foreign bodies in the form of fractured IV cannula.

\section{Case 1}

A 28 year old male with history of prior hospitalization presented with complaints of foreign body sensation over the right forearm since the time of discharge. Patient had been admitted to a private nursing home 3 days prior and an IV catheter had been inserted over the extensor aspect of the right forearm to administer fluids and antibiotics in view of dehydration. Hospital stay was uneventful and patient made a full recovery. At the time of discharge, the IV Cannula was removed by staff nurse and the patient was sent home. No complications were suspected. Patient presented to our OPD with foreign body sensation over the site of previous IV catherization. Clinical impression was thrombophlebitis \& patient was explained. 
However on the request of patient, X-ray of local part was done. X-ray showed a linear foreign body of around $2 \mathrm{~cm}$ along the presumed course of the superficial vein (Fig 1a).

Patient was explained to allay anxiety and was taken up for local exploration under General Anaesthesia. The vein was identified and dissected out from surrounding tissues and presence of foreign body within confirmed on palpation. The vein was clamped proximally using a Bulldog clamp, the vein hitched up with linen ties, and a venotomy done. A $2.3 \mathrm{~cm}$ fragment of cannula was retrieved from within the vein (Fig 1 b,c) and venotomy was closed with 5-0 Prolene sutures. Patient was discharged on Day 2 post surgery.

\section{Case 2}

In another case, a 30 year old male was referred from a private hospital. Patient gave a history of 20G IV catheter insertion in the right cephalic vein for administration of contrast during a Computed Tomography (CT) scan. On the way back to the ward the patient had a fall and suffered trauma to the right wrist leading to breakage of the IV cannula and bleeding from the site of insertion. Patient complained of pain and foreign body sensation over the radial aspect of right wrist. Bleeding was controlled by pressure bandage. Xray of local part revealed a linear foreign body near the site of catherization suggestive of broken fragment of IV cannula. (Fig. 2a)

The patient was taken up for Local Exploration under General Anaesthesia. The vein was identified and venotomy was done. The lumen was explored proximally and distally for a length of 5-7 cms, but no evidence of the catheter fragment was found. Intra-operative C-Arm was used followed by dissection of the soft tissue surrounding the vein to reveal extra luminal position of the fragment (Fig 2b). The cannula was retrieved from soft tissue. Venotomy was closed with 5-0 Prolene. Patient made uneventful recovery.

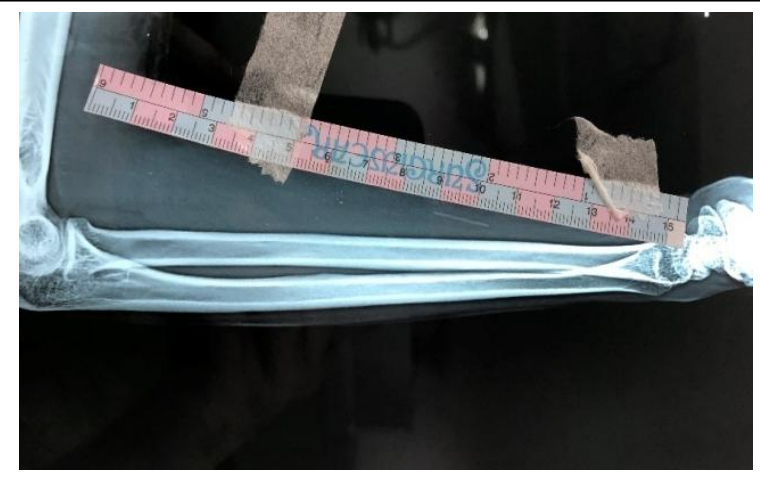

Figure 1 (a) X-ray showing presence of foreign body

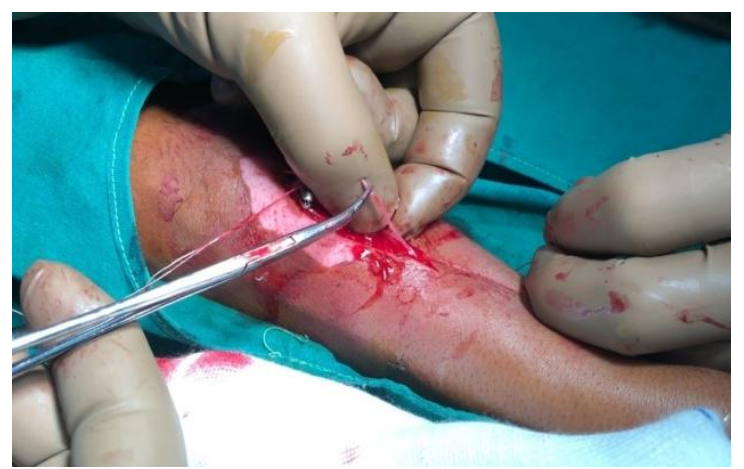

Figure 1 (b) Cannula retrieved through venotomy

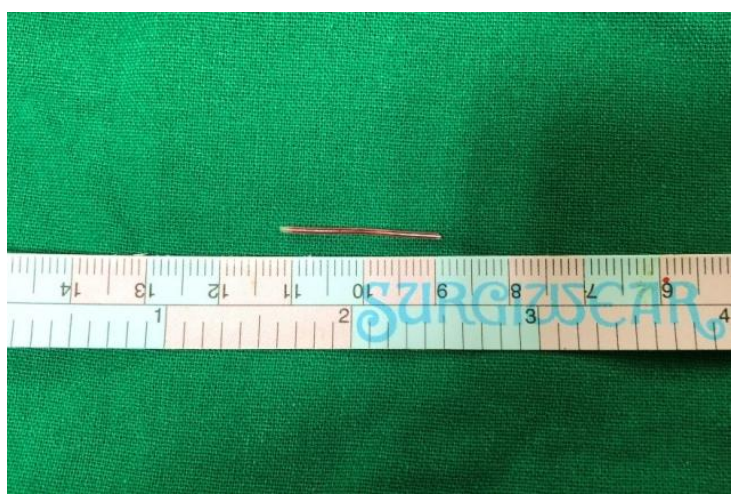

Figure 1 (c) $2.3 \mathrm{~cm}$ cannula fragment.

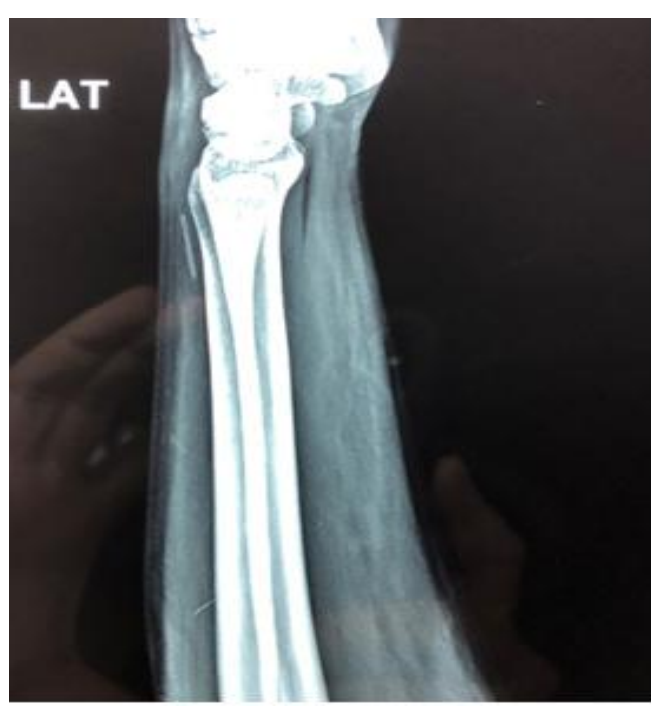




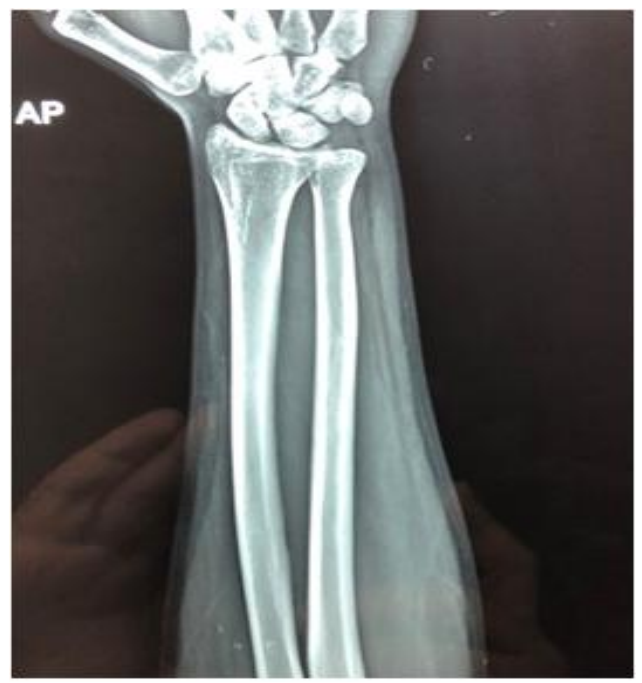

Figure 2 (a) Xray right forearm in AP and Lateral views.

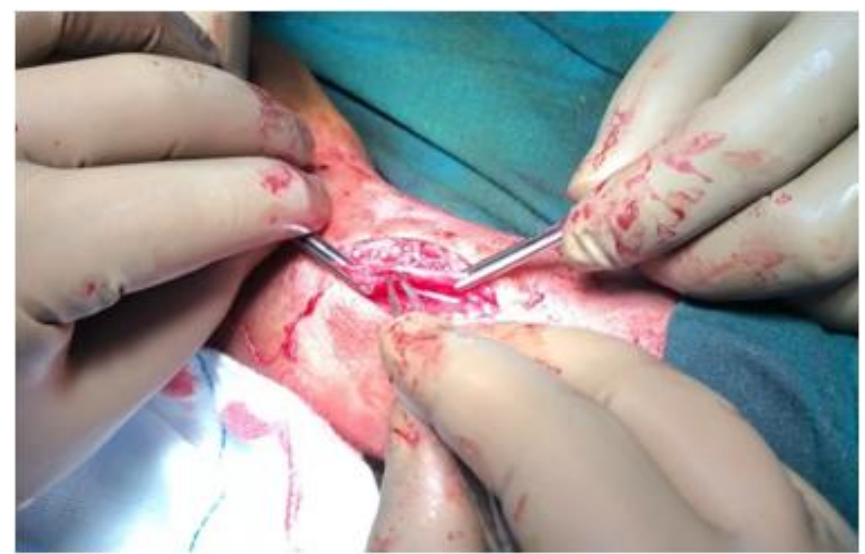

Figure 2 (b) IV cannula found outside the vein

\section{Discussion}

Insertion of anintravascular cannula is one of the most common invasive procedures used for administration of fluids and IV medications. When performed properly, peripheral IV placement is a safe procedure with little serious risk. Nevertheless, a number of potential complications have been described such as phlebitis, extravasation of IV fluids, bruising, and hematoma formation. Less commonly reported complications include venous air embolism, pneumocephalus, skin necrosis, bacteremia, compartment syndrome, nerve, arterial and tendon injury, and venous aneurysm formation. ${ }^{[1]}$

Spontaneous fracture and migration of intravenous cannula is a rare but known complication first described by Turner et al in 1954. ${ }^{[2]}$ Quality of materials, repeated attempts of catheterization with the same cannula ${ }^{[3]}$, uncooperative patients and direct trauma to the IV line while in situ are thought to contribute to the incidence of fractured IV cannula ${ }^{[4]}$.

This risk can be reduced by adhering to guidelines, avoiding repeated attempts with the same cannula, avoiding lower extremity IV placement, minimizing catheter movement, placing the smallest suitable catheter size, and removing the catheter as soon as possible. Catheters placed in emergency circumstances are more prone to complications.

Apart from IV cannula, the growing application of intravascular tools in both diagnostic and therapeutic procedures and the more widespread use of percutaneously placed embolization and prosthetic material has seen an increase in the overall incidence in recent years, along with increased risk of venous and arterial embolization of foreign material. ${ }^{[5]}$ These include Swan Ganz catheters, hyperalimentary catheters, ventriculoatrial shunts, pace maker electrodes, angiographic catheters or guide wire fragments, angioplasty equipment components, vascular stents, embolization material, caval filters, broken puncture needles in drug addicts, and foreign projectiles.

Management in these cases proceeds with early identification and diagnosis by clinical examination of the local part along with X-ray imaging to confirm the presence of foreign body. In cases where foreign body has migrated to deeper tissues or embolized to central vessels, computed tomography with $3 \mathrm{D}$ reconstruction may offer better visualization and localization.

Surgical retrieval of the foreign body should be carried out under anaesthesia, involving careful dissection, identification, and venotomy of the involved vessel, and gentle retrieval of the foreign body. It is important to keep in mind the possibility of extra-vascular migration of the foreign body into surrounding tissues. The use of Intra-operative $\mathrm{C}$-arm provides real-time imaging for accurate identification and localization in such cases. 
With the advent of Interventional Radiology, minimally invasive methods of intravascular foreign body foreign body retrieval are a viable and safe option, especially in cases where the foreign body is present in the deeper or central venous system. ${ }^{[5]}$ The procedure can be done under local anaesthesia on outpatient basis under angiographic guidance using loop-snares, Dormia baskets or urological forceps. It provides a safe and relatively complication free option, obviating the need for extensive surgery. ${ }^{[6]}$ However, its use is restricted by the cost and limited availability exclusive to higher care centres.

\section{Conclusion}

Intravenous retention of a broken IV Cannula is an uncommon complication of a common procedure. Whenever there is trauma to the iv site, it should be removed with care to confirm that it is removed in its entire length. If broken, the cannula may migrate proximally intravenously or extraluminally as is evident by the above cases. The use of C-Arm is essential during such explorations. By implementing universal guidelines such complications can be avoided. In presence of complications, early exploration after localization should be the treatment of choice.

\section{Acknowledgement}

Professor A.H. Bhandarwar for guidance \& support to publish this paper.

\section{Conflict of Interest-None}

Financial Disclosure: None

\section{References}

1. Singh S, Prakash J, Shukla VK, Singh LK. Intravenous catheter associated complications. J Assoc Physicians India 2010;58:194-6

2. Turner DD, Sommers SC. Accidental passage of a polyethylene catheter from cubital vein to right atrium; report of a fatal case. N Engl J Med 1954; 251:744-5.
3. Arun O, BaharOc,Gunduz E, Mehmet Oc, Duman A. Fracture of an intravenous cannula in the vein due to reinsertion of the guide needle: A case report. JournalCardiovascular Surgery 2014; 2:28-9

4. Khoo PJ, Tay KL, Jamaluddin AA, Gunasaker D. Self-inflicted and iatrogenic peripheral intravenous cannula fracture: A case report. Ann Med Surg (Lond). 2018;33:44-6.

5. Dondelinger, R. F., Lepoutre, B., \&Kurdziel, J. C. (1991). Percutaneous vascular foreign body retrieval: Experience of an 11-year period. European Journal of Radiology, 1991; 12: 4-10

6. Fisher RG, Ferreyro R. Evaluation of current techniques for nonsurgical removal of intravascular iatrogenic foreign bodies. Am J Roentgenol 1978; 130: 541-8

7. Singh A, Kaur A, Singh M, Kaur S. CT Guided Removal of Iatrogenic Foreign Body: A Broken Intravenous Cannula. J Clin Diagn Res. 2015; 9:28-9. 